\title{
Immunogenicity of Multiple Antigenic Peptides (MAP) Based on B and T cell Epitopes of E2 Glycoprotein of Chikungunya Virus in Murine System
}

\author{
Nagar $\mathrm{PK}^{1}$, Manmohan $\mathrm{P}^{2}$, Kolli $\mathrm{VK}^{3}$ and Rao $\mathrm{DN}^{* 1}$ \\ ${ }^{1}$ Department of Biochemistry, All India Institute of Medical Sciences (AIIMS), Ansari Nagar, New Delhi, India \\ ${ }^{2}$ Divisions of Virology, Defense Research \& Development Establishment (DRDE), Gwalior, India \\ ${ }^{3}$ Department of Biochemistry, GITAM Institute of Medical Sciences \& Research (GIMSR), Visakhapatnam, India
}

${ }^{*}$ Corresponding author: Rao DN, Professor and Head (Retd.), Department of Biochemistry, All India Institute of Medical Sciences, Ansari Nagar, New Delhi-110029, India, Tel: +91 9868592706, E-mail: dnrao311@ rediffmail.com

Citation: Nagar PK, Manmohan P, Kolli VK, Rao DN (2017) Immunogenicity of Multiple Antigenic Peptides (MAP) Based on B and T cell Epitopes of E2 Glycoprotein of Chikungunya Virus in Murine System. J Immunol Infect Dis 4(2): 201. doi: 10.15744/2394-6512.4.201

Received Date: November 06, 2017 Accepted Date: December 18, 2017 Published Date: December 20, 2017

\begin{abstract}
Objective: Chikungunya is a viral disease caused by positive sense single stranded RNA virus. High fever, myalgia, arthralgia, body rashes are the characteristic features of Chikungunya transmitted by Aedes mosquitoes. We aim to demonstrate that dominant epitopes of envelope $\mathrm{E} 2$ protein can be used for diagnostic purposes as well as vaccine design.

Methods: Multiple Antigenic Peptide (MAP) approach was used based on B and T cell epitopes of E2 protein. Humoral and cell mediated responses were studied in outbred and inbred $\mathrm{H}-2^{\mathrm{d}}$ mice. Different groups of mice were immunized intramuscularly with or without adjuvant (CpG ODN and murabutide) in PLGA microspheres.

Results: MAP entrapped in microspheres with CpG ODN showed highest IgG peak titer $(2,98,000)$ with IgG subclass, mostly IgG2a/2b distribution. MAP's antisera showed significant immunoreactivity with individual peptides. During thymidine incorporation assay for T cells, all the MAPs showed high lympho-proliferative response. Cytokine profile was dominated by Th1 and Th17 response. Thus, all the MAPs showed high humoral and cell mediated response with CpG/ murabutide adjuvant. MAP's antisera showed significant in vitro neutralization of CHIKV strain in vero cells.
\end{abstract}

Conclusion: MAP appears to be an alternate approach for vaccine design.

Keywords: Multiple Antigenic Peptide; B and T cell Response; Chikungunya; E2 protein

\section{Introduction}

Chikungunya is a febrile illness caused by positive sense RNA virus that belongs to genus Alphavirus of the Togaviridae family. Chikungunya virus (CHIKV) is an enveloped virus with four non-structural (nsP1-4) and five structural proteins (C, E1-3, 6K) [1]. First time Chikungunya disease was identified in East Africa in the early 1952 [2,3]. CHIKV symptoms start 4 to 7 days after exposure and mostly resolve within two weeks of acute phase. Although the acute phase lasts approximately 2 weeks, joint pain can persist for months or even years following initial infection [4,5]. Currently there is no licensed vaccine or effective therapy available for prevention or treatment of CHIKV. However, efficacy of recombinant and attenuated vaccine was tried in murine and primate models through the generation of neutralizing antibodies [6-10]. We focused our attention on E2 glycoprotein because of its involvement in host-cell receptor interaction with immune cells [11]. Thus, it can be a good target for virus neutralization/ blocking antibody for receptor on the antigen presenting cells by the virus. Previous studies showed that monoclonal antibody against the specific epitope of E2 protein protected mice or inhibited virus entry inside the vero cells after CHIKV challenge [1215]. These observations prompted us to use $B$ and $T$ cell epitopes of $E 2$ protein in developing MAP based immunogen. We identified few dominant epitopes on E2 protein based on murine data and reactivity with convalescent human sera [16-18]. T cell epitopes were identified on the basis of in vitro $\mathrm{T}$ cell proliferation and cytokines profile $[17,18]$. In the present study, these epitopes were assembled together as a MAP construct for designing immunogen for CHIKV. MAP allows the incorporation of multiple copies of a single or different epitopes in a defined manner. Previous studies showed improved immune response can be achieved for different disease using MAP approach [19-21]. MAP entrapped in PLGA microspheres with CpG ODN or Murabutide adjuvant 
showed high antibody titers and produced virus neutralizing antibody in vitro. MAP also showed cell mediated immune response in terms of high stimulation index and generated protective or beneficial cytokines. Thus, assembling as a MAP proved to be a better immunogen.

\section{Methods}

\section{Synthesis of multiple antigenic peptides (MAP)}

Dominant B and T cell epitopes of E2 protein were constructed as MAPs using Fmoc chemistry. Three MAPs viz. MAP-1, MAP-2, MAP-3 were synthesized on Gly-HMP-Tantageyl resin [21]. All the MAPs were purified by HPLC and characterized by amino acid analysis and molecular weight. Following MAPs were constructed with different B and T cell epitopes.

MAP-1

$\mathrm{K} \rightarrow$ HCPDCGEGHSCHSPV(2817-2831)

$\mathrm{K} \longrightarrow$ IGTDDSHDWTKLRY(2855-2868)

K GFTDSRKISHSCTHPFHHD (2913-2931)

K PVIGREKFHSRPQHGGKELP(2933-2952)
MAP-2

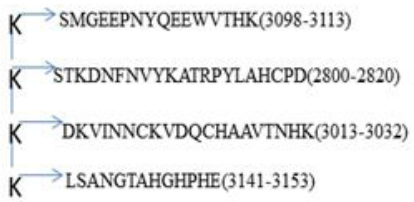

MAP-3

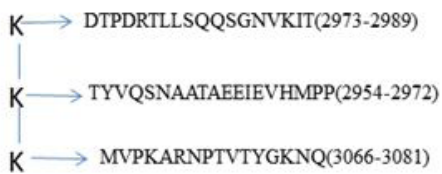

\section{Experimental Mice}

Six to eight weeks old outbred and BALB/c $\left(H-2^{d}\right)$ mice were used. Six to eight mice were used in each group. Experiments were done according to the guidelines of AIIMS Ethics as well as CPCSEA, Ministry of Social Justice, Government of India.

\section{Entrapment of MAPs in PLGA microparticle, particle size and morphology}

MAPs were entrapped in microspheres using poly (DL-lactide-co-glycolide; 50:50) (Sigma, USA) by double solvent evaporation method (water-in-oil-in-water) [22]. Percentage of entrapment of MAPs in microspheres was estimated by bicinchoninic acid (BCA) method (Sigma, IL, USA) and it was in the range of 53-64\%. The size was between 2-8 $\mu$ m. Morphology of microspheres was found to be spherical.

\section{Immunization of mice and Sera collection}

PLGA microspheres containing 40 $\mu$ g of MAPs was dissolved in $40 \mu$ of PBS with $5 \mu \mathrm{g}$ CpG-ODN 1826 (TCCATGACGTTCCTGACGTT) (Coley Pharmaceuticals, USA) or murabutide (Invivogen,USA) adjuvants. Different group of mice were immunized intramuscularly with MAPs in microspheres (MS), MAPs in MS with $5 \mu \mathrm{g}$ of CpG ODN and MAPs in MS with $5 \mu \mathrm{g}$ of murabutide at the thigh region on day 0 . Booster dose of $20 \mu \mathrm{g}$ of MAPs with $5 \mu \mathrm{g}$ of adjuvants was given on days 23 and $42.0 .5 \mathrm{ml}$ blood was collected from retroorbital plexus on the days $28,42,60,90,120$. Antisera was separated and stored at $-20^{\circ} \mathrm{C}$ till use.

\section{Reactivity of MAP with E2 antisera and MAP antisera with their respective peptides and E2 protein}

MAP's reactivity with E2 protein antisera were tested by direct binding assay. ELISA plates were coated with different MAPS (100ng/well). Plates were blocked with 5\% milk powder and washed with $0.05 \%$ of PBS tween-20. The antisera raised with E2 protein in outbred mice was added at a dilution of 1:200 onto the ELISA plates and incubated at $37^{\circ} \mathrm{C}$ for $2 \mathrm{~h}$. In the same manner, reactivity of individual peptides with MAPs antisera was also tested. Plates were coated with respective peptides (200ng/well) and incubated with MAPs antisera with two-fold serial dilution and incubated at $37{ }^{\circ} \mathrm{C}$ for $2 \mathrm{~h}$. To check the reactivity of MAPs with peptide antisera, plates were coated with different MAPs (200ng/well) and incubated with different peptide antisera at a dilution of 1:200 and incubated at $37^{\circ} \mathrm{C}$ for $2 \mathrm{~h}$. After washing, goat anti-mouse IgG-HRP (1:1000 dilutions) was added and kept at $37{ }^{\circ} \mathrm{C}$ for $1 \mathrm{~h}$ and color was developed using OPD as a chromogen and $\mathrm{H}_{2} \mathrm{O}_{2}$ as a substrate [23].

\section{Humoral response (Peak antibody levels)}

MAP specific antibody levels were estimated using standard ELISA protocol. Briefly, 96 well microtiter plates (Immulon II HB, Dynatech) were coated with $200 \mathrm{ng} /$ well of each MAP (100 $\mu \mathrm{l} /$ well), non-specific binding sites were blocked with 5\% milk powder. After washings, serial two-fold dilution of different MAP antisera was added to measure IgG peak antibody titers. Color was developed as described above. The titers were expressed as the highest serum dilution giving an absorbance higher than that of pre-immune sera. 


\section{Estimation of IgG subclass}

IgG subclass (IgG1, IgG2a, IgG2b and IgG3) estimation was done as per manufacturer's instructions using isotyping kit ISO-2 (Sigma, USA). $100 \mathrm{ng} /$ well of MAP were coated on ELISA plates and MAP pooled sera of each group was added at 1:200 dilution and color was developed as described above.

\section{Memory response}

To check the memory or amnestic response, mice were immunized with $20 \mu \mathrm{g}$ of native E2 protein with $5 \mu \mathrm{g}$ CpG ODN on day 120 and bleeds were collected on day 135 and IgG antibody titers were estimated as described above.

\section{In vitro $\mathrm{T}$ cell proliferation assay}

Microspheres containing the respective MAPs were injected intramuscularly to outbreed and inbred $\mathrm{H}-2^{\mathrm{d}}$ mice with a primary dose of $40 \mu \mathrm{g}$ MAP equivalent on day 0 with $5 \mu \mathrm{g}$ CpG ODN/ Murabutide. Booster dose of $20 \mu \mathrm{g}$ of respective MAP and 5 $\mu \mathrm{g}$ CpG/ Murabutide was given on day 10. In case of E2 protein, mice were immunized with primary dose of $30 \mu \mathrm{g}$ with $5 \mu \mathrm{g}$ CpG ODN on day 0 followed by booster dose of $15 \mu \mathrm{g}+5 \mu \mathrm{g}$ CpG ODN on day 10. Splenocytes (devoid of B cells by panning with anti-mouse immunoglobulin) were cultured in triplicate wells $(2 \times 105$ cells/well) on day 21 in RPMI 1640 medium (300 $\mu 1 /$ well) containing the appropriate antibiotics. Following variables were used to stimulate splenocytes.

1. Splenocytes were primed with E2 protein in vivo and in vitro stimulated with native E2 protein (5,10 and $25 \mu \mathrm{g} /$ well) or with individual MAPs $(10,25,50 \mu \mathrm{g} /$ well $)$.

2. Splenocytes were primed with individual MAPs in vivo and in vitro stimulated with native E2 protein and cognate MAP (10, 25, and $50 \mu \mathrm{g} /$ well).

PHA ( $2 \mu \mathrm{g} /$ well) was used as positive control. After $72 \mathrm{~h}$ of culture, $200 \mu \mathrm{l}$ of culture supernatant was collected from each well and stored at $-70{ }^{\circ} \mathrm{C}$ for cytokine estimation. The cultures were pulsed with $\left[{ }^{3} \mathrm{H}\right]$ thymidine $0.5 \mu \mathrm{Ci} /$ well and after $18 \mathrm{~h}$, cells were harvested. Thymidine incorporation was measured by a liquid $\beta$ scintillation counter. Stimulation index (SI) was calculated. The data was presented as mean $\mathrm{SI} \pm \mathrm{SD}$ of triplicate wells.

\section{Cytokine level measurement}

The levels of Th1, Th2, Th17 and pro-inflammatory (IL-1 $\beta$, IL2, IL-4, IL-10, IL-12, IL-17, TNF- $\alpha$, IFN- $\gamma$ ) cytokines were measured in the culture supernatant using sandwich ELISA (e-Biosciences). Data was presented as mean concentration of cytokine (pg/mL) \pm S.D. of triplicate wells.

\section{Neutralization assays}

90\% plaque reduction neutralization test $\left(\mathrm{PRNT}_{90}\right)$ in vero cells was done by reported procedure using two-fold serial dilution of MAPs antiserum.(23) Plaque was counted and titers were calculated and expressed as the reciprocal of serum dilution yielding $\geq 90 \%$ reduction $\left(\mathrm{PRNT}_{90}\right)$ in the number of plaques.

\section{Statistical analysis}

The data on MAPs specific IgG, IgG subclass, T cell proliferation and cytokine levels were compared by non-parametric KruskalWallis one-way analysis of variance by ranks. The levels of significance ( $p$ value) were compared between different formulations of MAPs \& Mean antibody titers in sera were compared with student's $t$ - test.

\section{Results}

\section{Antibody peak titer of MAPs antisera at different intervals}

All the MAPs were found to be immunogenic and showed high IgG titers with all formulations on days 28, 42, 60, 90 and 120. MAP entrapped in microspheres (MS) showed serum IgG titers ranging from 90,000 to 1,70,000 in outbred and $\mathrm{H}-2^{\mathrm{d}}$ mice respectively (Figure 1A and Supplementary 1A). MAP with murabutide showed antibody titer ranging from 1,75,000 to 1,82,000 (Figure 1B and Supplementary 1B) and MAP with CpG showed antibody titers ranging from 2,50,000 to 2,98,800 in both strain of mice (Figure 1C and Supplementary 1C). Among all formulations used, MAP+CpG formulation showed significantly ( $\mathrm{p}<0.0001)$ high serum IgG titers in both strains of mice. With all formulations irrespective of strains used, maximum titers were observed on day 60 which was maintained until day 90 with gradual decline on day 120 . Overall MAP+CpG showed significantly $(\mathrm{p}<0.0001)$ higher peak antibody levels followed by MAP+murabutide and MAP in microspheres in both strains of mice.

\section{Individual peptides and E2 protein reactivity with MAPs antisera, MAPs reactivity with E2 protein antisera}

MAPs response to individual peptides was measured in mice in terms of peak antibody titer on $60^{\text {th }}$ day. Antisera generated 
with MAP + CpG formulation was found to be significant $(\mathrm{p}<0.05)$ in terms of peak antibody titre in outbred mice. Peptide E2P5 of MAP-1 showed highest endpoint titer as compared to other peptides. Peptides E2P5 showed maximum peak antibody titers upto 1,10,000, E2P3 of MAP-2 showed 1,25,000, E2P10 and E2P16 of MAP-3 showed 1,00,000 and 122000 peak antibody titers respectively (Figure 2C). Similar observation was seen in $\mathrm{H}-2^{\mathrm{d}}$ mice too (Figure S2B). The E2 protein showed significant $(\mathrm{P}<0.001)$ immunoreactivity with MAP1-3 antisera on day 60 of outbred and H-2 ${ }^{\mathrm{d}}$ mice (Figure $2 \mathrm{~B}$ and Supplementary $\left.2 \mathrm{~A} \& \mathrm{~B}\right)$. The study concludes that all the MAPs induced antibodies to different epitopes of E2. In vice versa MAP1-3 also showed significant immunoreactivity with E2 antisera (Figure 2A).

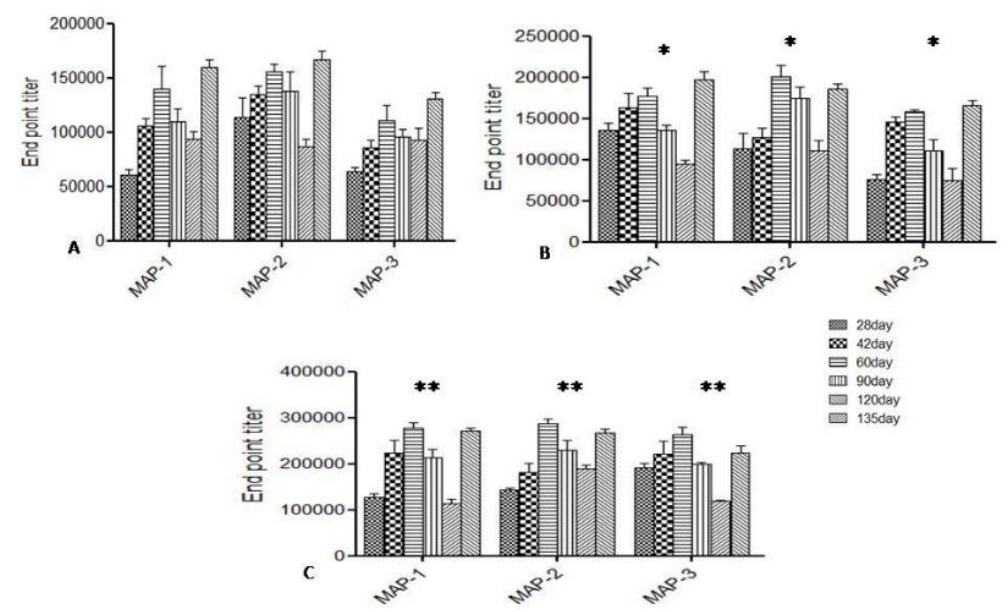

Figure 1: MAP specific IgG peak titer of different time intervals in outbred mice, after intramuscular immunization of MAPs; (A) Endpoint titer for MAP in microsphere; (B) Endpoint titer for MAP in microsphere with murabutide; (C) Endpoint titer for MAP in microsphere with CpG adjuvant.100ng/100 $\mu \mathrm{L}$ per well of MAPs, was coated on ELISA plates and respective MAPs antisera were added with two-fold serial dilutions following goat-antimouse-IgG-HRPO was added and finally color was measured at $492 \mathrm{~nm}$. EM $+\mathrm{CpG}$ ODN was used as negative control. The titers were expressed as the highest serum dilution giving an absorbance higher than that of negative control. Data of two independent experiments expressed as mean $\pm \mathrm{SD}, \mathrm{P}<0.001, \mathrm{P}<0.0001(\mathrm{MAP}+\mathrm{CpG})$

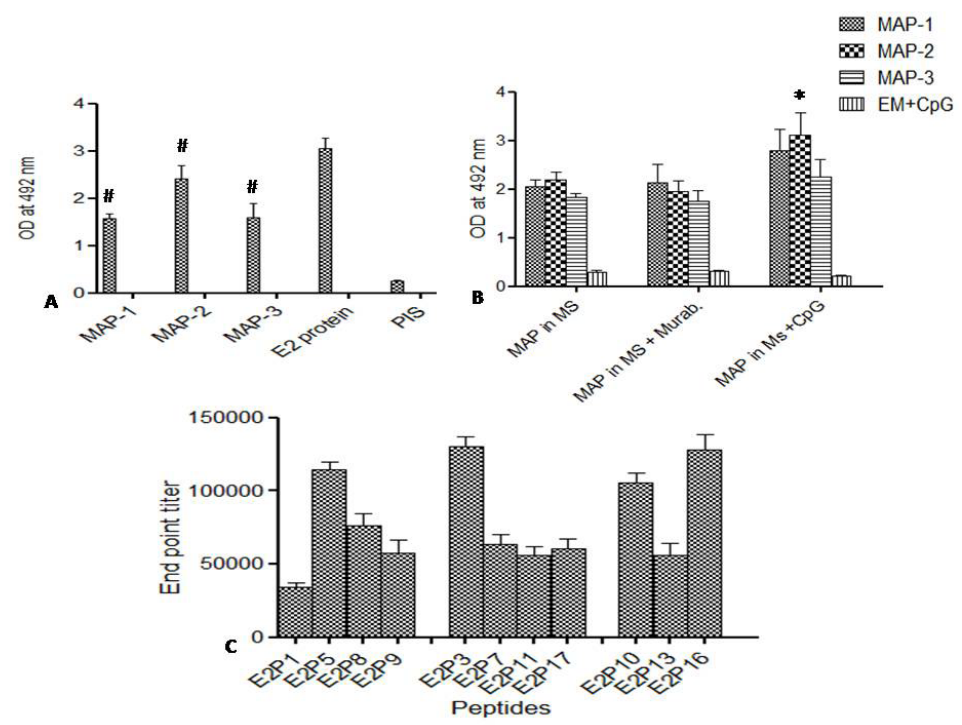

Figure 2: (A) Immunoreactivity of MAPs with E2 protein antisera, 100ng/100 $\mu \mathrm{L}$ MAPs were coated onto ELISA plates and E2 protein antisera was added at 1:200 dilution, color was developed and absorbance was taken at $492 \mathrm{~nm}$. Pre-immune sera (PIS) were used as negative control. \# indicate p < 0.001; (B) Direct binding assay of MAP antisera of 60 day with E2 protein raised in outbred mice, 100ng/100 $\mu \mathrm{L}$ of E2 protein was coated on ELISA plates and individual MAPs antisera was added at 1:200 dilution. Reactivity was checked using ELISA protocol. Empty microspheres (EM) + CpG ODN were taken as negative control. * indicate $\mathrm{p}<0.05$ compared to MAP in MS + Murabitide and MAP in MS; (C) Endpoint titer of individual peptide with their respective MAP antisera. 200ng of each peptide was coated on ELISA plate and MAP antisera were added with two-fold serial dilutions. Goat-antimouse-IgG -HRPO was added and color was measured at $492 \mathrm{~nm}$. Data of two independent experiments expressed as mean $\pm \mathrm{SD}$

\section{IgG subclasses estimation in antisera}

Isotyping was done for antisera of outbred and inbred mice. In case of outbred mice, IgG2a/IgG2b antibody levels were significantly 
high $(\mathrm{P}<0.001)$ for MAP-1, 2. While MAP-3 showed equal distribution of IgG1 and IgG2a/IgG2b subtypes (Table $1 \mathrm{~A})$. The isotypes ratio (IgG2a/IgG1) was found to be $>1.0$ with MAP+CpG formulation for MAP-1 and MAP-2 showing Th1 dominant immune response. MAP- 3 showed isotypes ratio $\leq 1$ thereby showed a mixed Th1/Th2 response. The maximum isotype levels were observed on day 60 sera. Similar isotype pattern was observed in inbred H-2 ${ }^{\mathrm{d}}$ strain (Table 1B).

\begin{tabular}{|c|c|c|c|c|c|}
\hline MAP & $\begin{array}{c}\text { IgG } \\
\text { subclass }\end{array}$ & $\mathbf{4 2}$ day & $\mathbf{6 0}$ day & $\mathbf{9 0}$ day & $\begin{array}{c}\mathbf{1 3 5} \\
\text { day }\end{array}$ \\
\hline \multirow{4}{*}{ MAP-1 } & IgG1 & 0.488 & 0.692 & 0.589 & 0.692 \\
& IgG2a & $1.498^{*}$ & $1.745^{*}$ & $1.164^{*}$ & $1.769^{*}$ \\
& IgG2b & $1.262^{*}$ & $1.932^{*}$ & $1.378^{*}$ & $1.695^{*}$ \\
\hline \multirow{4}{*}{ MAP-2 } & IgG1 & 0.501 & 0.645 & 0.568 & 0.689 \\
& IgG2a & $1.091^{*}$ & $2.167^{*}$ & $1.467^{*}$ & $2.346^{*}$ \\
& IgG2b & $1.340^{*}$ & $2.094^{*}$ & $1.562^{*}$ & $2.290^{*}$ \\
\hline \multirow{3}{*}{ MAP-3 } & IgG1 & 1.002 & 1.674 & 1.023 & 1.580 \\
& IgG2a & 1.109 & 1.542 & 1.132 & 1.532 \\
& IgG2b & 1.245 & 1.564 & 1.145 & 1.450 \\
\hline
\end{tabular}

Table $1 \mathrm{~A}$

\begin{tabular}{|c|c|c|c|c|c|}
\hline MAP & $\begin{array}{c}\text { IgG } \\
\text { subclass }\end{array}$ & $\mathbf{4 2}$ day & $\mathbf{6 0}$ day & $\mathbf{9 0}$ day & $\begin{array}{c}\mathbf{1 3 5} \\
\text { day }\end{array}$ \\
\hline \multirow{3}{*}{ MAP-1 } & IgG1 & 0.570 & 0.769 & 0.406 & 0.567 \\
& IgG2a & $1.124^{*}$ & $1.890^{*}$ & $1.284^{*}$ & $1.680^{*}$ \\
& IgG2b & $0.949^{*}$ & $2.189^{*}$ & $1.432^{*}$ & $1.721^{*}$ \\
\hline \multirow{3}{*}{ MAP-2 } & IgG1 & 0.501 & 0.745 & 0.512 & 0.490 \\
& IgG2a & $1.456^{*}$ & $2.230^{*}$ & $2.007^{*}$ & $2.452^{*}$ \\
& IgG2b & $1.280^{*}$ & $2.189^{*}$ & $1.601^{*}$ & $2.219^{*}$ \\
\hline \multirow{3}{*}{ MAP-3 } & IgG1 & 1.128 & 1.452 & 1.210 & 1.645 \\
& IgG2a & 1.245 & 1.396 & 1.189 & 1.452 \\
& IgG2b & 1.321 & 1.564 & 1.245 & 1.521 \\
\hline
\end{tabular}

Table 1B

${ }^{*}$ indicates $\mathrm{p}<0.001$ compared to IgG1antibody levels.

Table 1: Estimation of peptide specific IgG isotypes antibodies (IgG1, IgG2a and IgG2b) in pooled sera (MAP in MS+ $\mathrm{CpG}$ ) of outbred mice (A) and $\mathrm{H}-2^{\mathrm{d}}$; (B) on days 42, 60, 90 and 135

\section{In vitro $\mathrm{T}$ cells proliferation}

All the four MAPs showed higher stimulation index (SI) during in vitro stimulation of splenocytes. E2 primed splenocytes of outbred mice when stimulated with different MAPs, MAP-2 showed highest stimulation index. All the MAPs showed stimulation index in the range $30 \pm 1.23$ to $41 \pm 2.87$. Similarly, stimulation of MAP primed splenocytes of outbred mice with respective MAPs, MAP-1, MAP-3 showed stimulation index $36 \pm 4.89,38 \pm 5.12$ at $25 \mu \mathrm{g} /$ well while MAP-2 showed $45 \pm 3.45$ at $25 \mu \mathrm{g} /$ well respectively (Fig.3A). E2/MAPs primed splenocytes of inbred mice when stimulated with MAPs also showed high stimulation index $30 \pm 4.89$, $42 \pm 5.12,34 \pm 4.89$, and $43 \pm 5.12$ (Figure S2C). Results indicate that all the MAPs generated high lymphoproliferative response in outbred and inbred mice, while MAP-2 appears to be a superior construct over others.

\section{Memory response}

B-cell memory response is a necessary feature to develop a vaccine as memory helps in quick antibody synthesis and clearance of infection on re-exposure to the pathogen. Amnestic response was confirmed by giving a booster with E2 protein on day 120 and response was evaluated on day 135 for all the MAPs. They showed memory response through generation of high antibody levels (Figure 1A, B and C and Supplementary 1A, B and C). It indicates that MAPs had the potential to induce the amnestic/secondary immune response after challenge with native $\mathrm{E} 2$ protein.

\section{Cytokines' levels}

MAP 1-3 showed significantly $(\mathrm{p}<0.01)$ high IL-1 $\beta$, IL-12, IL-2 and IL-17A cytokine levels when CpG was used as an adjuvant. The levels of IL-1 $\beta$, IL-2, IL-12 and IL-17A cytokines were found to be significant with a range of $1022-1208 \mathrm{pg} / \mathrm{mL}(p<0.005)$, $160-196 \mathrm{pg} / \mathrm{mL}(p<0.001), 250-325 \mathrm{pg} / \mathrm{mL},(p<0.05)$ and $184-298 \mathrm{pg} / \mathrm{mL}(p<0.001)$ respectively (Table 2$)$. MAP-1 and MAP-2 produced significantly high IFN $-\gamma(1480,1345 \mathrm{pg} / \mathrm{mL}, p<0.001)$ followed by MAP-3 $(970 \mathrm{pg} / \mathrm{mL}, p<0.05)$ when compared to unstimulated cells $(189 \mathrm{pg} / \mathrm{mL})$ (Table 2$)$. IL-4 levels were comparatively less $(P<0.001)$ with MAP-1 \& MAP-2 while MAP-3 has moderate levels (Table 2). However, IL-10 levels were insignificant for all the MAPs (Table 2). Significantly high $(P<0.005)$ levels of TNF- $\alpha$ was observed for MAP-1, MAP-2 and MAP-3 (Table 2). IL-1 $\beta$, TNF- $\alpha$, IFN- $\gamma$ cytokines level of MAP primed splenocytes stimulated with cognate MAP was in the range $1202-1480 \mathrm{pg} / \mathrm{mL}(P<0.001), 189-240 \mathrm{pg} / \mathrm{mL}(P<0.001), 1275-1489 \mathrm{pg} /$ $\mathrm{mL}(P<0.001)$ respectively. Rest of the cytokines levels were in the same range (Table 2$)$.

\begin{tabular}{|c|c|c|c|c|c|c|c|c|}
\hline Peptides & IL-1 $\beta$ & IL-2 & IL-4 & IL-10 & IL-12 & IL-17 & TNF- $\boldsymbol{\alpha}$ & IFN- $\boldsymbol{\gamma}$ \\
\hline MAP-1 & $1208 \pm 28.6$ & $196 \pm 5.89$ & $50 \pm 0.45$ & $45 \pm 4.67$ & $325 \pm 5.69$ & $184 \pm 12.8$ & $198 \pm 5.56$ & $1480 \pm 18.6$ \\
\hline MAP-2 & $1109 \pm 6.81$ & $160 \pm 6.89$ & $65 \pm 7.10$ & $38 \pm 2.89$ & $300 \pm 2.89$ & $254 \pm 7.98$ & $158 \pm 9.00$ & $1345 \pm 5.89$ \\
\hline MAP-3 & $1022 \pm 14.8$ & $189 \pm 4.56$ & $155 \pm 5.89$ & $52 \pm 2.09$ & $250 \pm 8.90$ & $298 \pm 5.89$ & $160 \pm 1.69$ & $970 \pm 9.90$ \\
\hline $\begin{array}{c}\text { E2 } \\
\text { protein }\end{array}$ & $378 \pm 1.89$ & $182 \pm 2.67$ & $164 \pm 12.0$ & $234 \pm 5.90$ & $440 \pm 5.86$ & $90 \pm 4.68$ & $89 \pm 14.9$ & $1720 \pm 16.8$ \\
\hline \multicolumn{7}{|c|}{ MAPs primed splenocytes stimulated with cognate MAPs } & & \\
\hline \multicolumn{7}{|c|}{} \\
MAP-1 & $1321 \pm 2.89$ & $187 \pm 2.60$ & $58 \pm 2.89$ & $45 \pm 2.67$ & $292 \pm 3.28$ & $245 \pm 5.90$ & $240 \pm 5.90$ & $1320 \pm 15.8$ \\
\hline
\end{tabular}




\begin{tabular}{|c|c|c|c|c|c|c|c|c|}
\hline Peptides & IL-1 $\beta$ & IL-2 & IL-4 & IL-10 & IL-12 & IL-17 & TNF- $\boldsymbol{\alpha}$ & IFN- $\boldsymbol{\gamma}$ \\
\hline MAP-2 & $1480 \pm 18.4$ & $156 \pm 2.89$ & $39 \pm 6.45$ & $49 \pm 8.96$ & $319 \pm 2.89$ & $268 \pm 12.8$ & $254 \pm 6.89$ & $1489 \pm 12.6$ \\
\hline MAP-3 & $1202 \pm 7.89$ & $198 \pm 12.9$ & $165 \pm 5.42$ & $56 \pm 5.45$ & $240 \pm 3.90$ & $360 \pm 10.8$ & $189 \pm 9.08$ & $1275 \pm 2.89$ \\
\hline 'EM & $392 \pm 8.90$ & $38 \pm 7.89$ & $45 \pm 1.90$ & $42 \pm 2.19$ & $102 \pm 4.50$ & $62 \pm 5.90$ & $60 \pm 2.89$ & $189 \pm 5.45$ \\
\hline
\end{tabular}

Data are representative of two independent experiments and are shown as Mean \pm SD

${ }^{1} \mathrm{EM}$ - Empty microspheres

Table 2: Cytokine levels in culture supernatant of splenocytes of outbred mice. Cultures were obtained when E2 protein primed splenocytes were stimulated with E2 protein or MAPs

In case of inbred mice $\mathrm{E} 2$ primed splenocytes stimulated with MAPs, IL-4 level for MAP-3 was 208pg/mL compared to unstimulated cells 49pg/mL. MAP-1, 2 produced significantly high IL-17 $(p<0.005)$ followed by MAP-3 $(p<0.001)$ as compared to unstimulated cells (Table S2). IFN- $\gamma$ levels for MAP1-3 were 1210-1689pg/mL compared to unstimulated cells $192 \mathrm{pg} / \mathrm{mL}$ (Table S1). Finally results conclude that MAP 1-3 showed significantly high level of IL-1 $\beta$, IL-2, IL-12, IL-17, TNF- $\alpha$, IFN- $\gamma$ while IL-4 and IL-10 levels were significantly less in culture supernatants of both outbred and inbred strains.

\section{In vitro neutralization assay}

Plaque reduction neutralization $\left(\mathrm{PRNT}_{90}\right)$ assay was performed to validate the neutralizing capacity of MAPs specific antisera against CHIKV. MAP + CpG antiserum of day 60 was used for in vitro neutralizing assay. Antisera of MAP-2 at 1:4000, MAP-1 at 1:2000 and MAP-3 at 1:500 dilutions showed 90\% inhibition of CHIK virus multiplication in vero cells (Figure 3A). E2 protein sera showed inhibition at 1:3000 dilutions (Figure 3B).

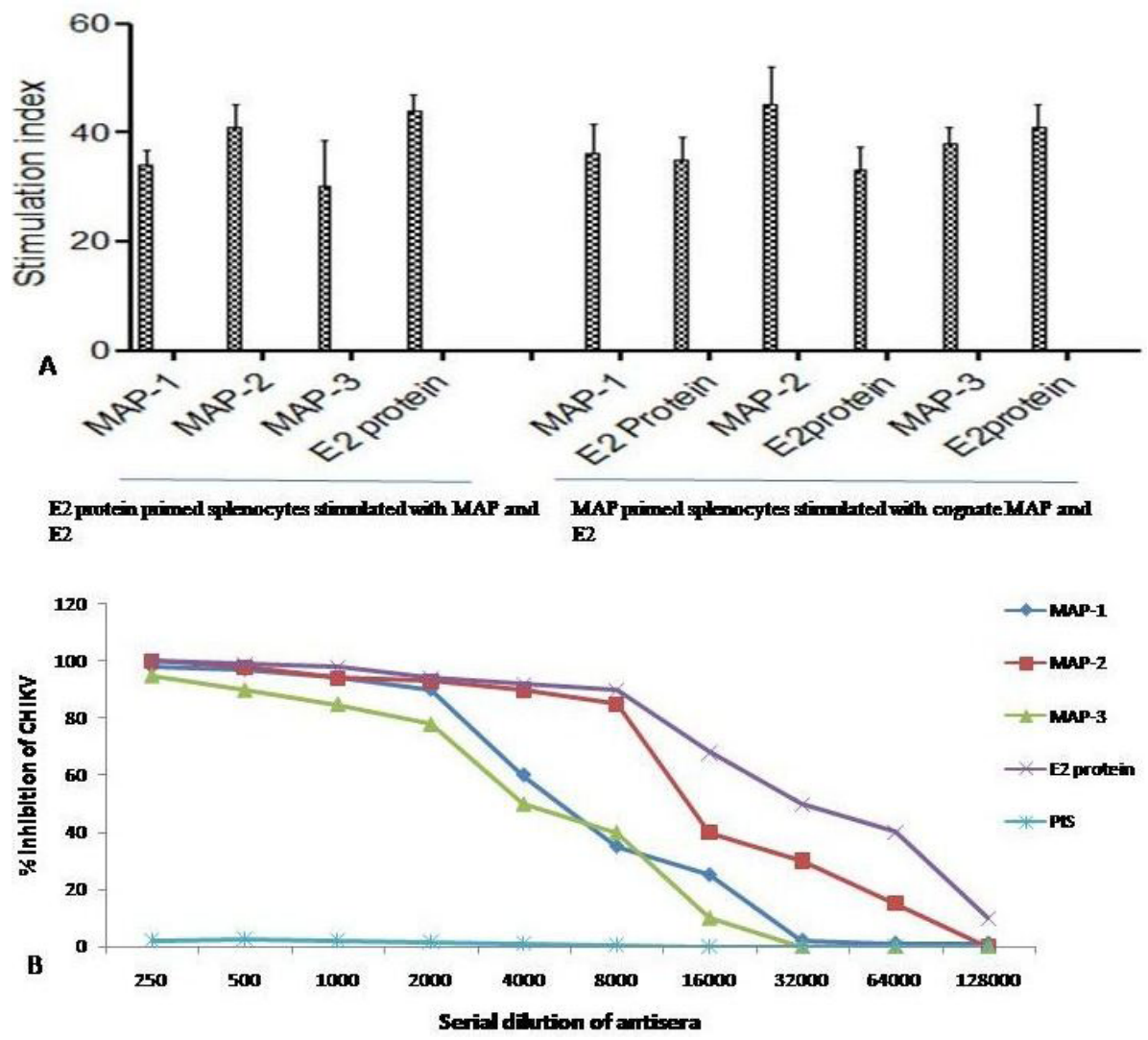

Figure 3: $\mathrm{T}$ cell lymphoproliferative response using $\mathrm{H}^{3}$-thymidine incorporation assay showing stimulation index (SI); (A) Outbred mice were primed with E2 protein and splenocytes in vitro stimulated with E2 protein and individual MAPs. Mice were primed with individual MAPs and splenocytes were stimulated with E2 protein and cognate MAPs. Spleen (SP) cells were cultured in 96 well plates. Phytohaemagglutinin (PHA) was used as a positive control. Empty microspheres (EM) stimulated cells were taken as negative control. Stimulation index was calculated by count per minutes (CPM) with stimulus divided by CPM without stimulus. Results of two independent experiments were expressed as mean SI value \pm SD; (B) In vitro neutralization of CHIKV by MAP antisera using vero cells. Serial dilutions of Abs were incubated with 200 PFU of CHIKV (DRDE 06). Plaques were counted and titers were expressed as the reciprocal of antibody dilution that showed $>90 \%$ plaque reduction. Pre-immunesera (PIS) was used as negative control and E2 antisera was used as positive control

\section{Discussion}

Peptide based immunogen are easy to synthesize and safe to use but its low molecular weight, high degradability and short half- 
life generally induce low immunogenicity [24,25]. MAPs' approach can be a better option for peptide based immunogens without a carrier molecule and to avoid genetic restriction. In this study different formulation of MAPs were used, MAP entrapped in microspheres with CpG ODN showed highest peak antibody titers and sustained over longer duration with strong memory response after boosting with native protein, followed by MAP + murabutide formulation as compared to without adjuvant. When MAP's antisera were tested with individual peptides, all peptides showed immunoreactivity with little variation, while few peptides showed dominance. These results prove that MAPs polyclonal antisera have different levels of peptide specific antibodies. IgG2a/ IgG2b were found to be highest $(\mathrm{P}<0.05)$ for MAP-1 and MAP-2 while MAP-3 showed equal distribution of IgG1 and IgG2a/IgG2b subclass. IgG2a and IgG2b antibodies are cytophilic in nature and are involved in protection. However, in case of CHIKV IgG1 and IgG2b subtype antibodies are found to be important in protection [26,27]. Further, MAP with CpG ODN showed enhanced T cell response. Cytokine profile showed Th1 and Th17 response which is known to be beneficial to the host. To understand the induced cell mediated immune response due to MAPs, cytokine profiles (Th1, Th2 and Th17) were measured. Tumor Necrosis Factor (TNF- $\alpha$ ) and IL-1 $\beta$ cytokine produced by macrophage/ monocytes during acute inflammation play an important role in the activation of innate and adaptive immunity $[26,28]$. Tumor Necrosis Factor (TNF- $\alpha$ ) and IL-1 $\beta$ cytokine play an important role in the activation of innate and adaptive response during pathogenic condition $[28,29]$. In the present study, all the MAPs showed significantly higher levels of IL-1 $\beta$ and TNF- $\alpha$, but these levels were comparatively low with E2 protein. This could be due to the presence of immunosuppressive epitopes on E2 protein. Thus, MAPs induced high CMI response by producing pro-inflammatory cytokines such as IL-1 $\beta$ and TNF- $\alpha$. The present study showed higher production of IFN- $\gamma$ with MAP-1, MAP-2, MAP-3. This indicates that IFN- $\gamma$ definitely has protection against CHIKV in agreement to an earlier study [30]. The levels of IL-4 cytokine were comparatively higher for MAP3 and E2 while MAP-1, MAP-2 showed Th1 and MAP-3 showed mixed Th1/Th-2 type response. Only E2 protein showed high levels of IL-10 cytokine. Because IL-10 is considered to be immunosuppressive and can cause termination of inflammatory response [31]. Another important cytokine IL-17 play protective roles in host defense against certain pathogens at epithelial and mucosal barriers and promote the up regulation of other inflammatory cytokines and chemokines [31]. In the present study, IL-17 level was significantly higher for MAP-1, MAP-2, MAP-3 but E2 could not generate significant levels of IL-17, thus MAPs can activate different cell lineages of immune system to clear CHIKV infection. Most important feature for antibody is in vitro neutralization of CHIKV virus multiplication in vero cells. When CHIKV infects the host in the presence of the neutralizing antibodies, the viral clearance is very fast [12,14]. All the MAPs showed high antibody peak titer, in vitro T cell proliferation with significant level of protective cytokines and virus neutralization. These are important criteria for a good vaccine. Thus, MAPs can be an alternate option for developing subunit vaccine for CHIKV.

\section{Conclusion}

Constructed MAPs derived for E2 protein based on B and T cell epitopes showed enhanced B and T cell response in murine model. MAPs induced high IgG antibody titer in outbred and $\mathrm{H}-2^{\mathrm{d}}$ mice. IgG2a/IgG2b Isotypes were dominant for MAP-1, MAP2 while MAP-3 showed equal distribution of IgG1 and IgG2a/IgG2b isotypic antibodies. MAP-1 and MAP-2 showed high T cell stimulation with mainly Th1 and Th17 type cytokines production. Interestingly, all the MAPs showed in vitro neutralization $\left(\mathrm{PRNT}_{90}\right)$ for CHIKV at different antisera dilutions on vero cells.

\section{Acknowledgements}

Authors are thankful to Defence Research and Development Organization (DRDO) and Department of Science and Technology (DST) for financial support. Mr. Pradeep Kumar Nagar is thankful to Department of Biotechnology (DBT) for his fellowship.

\section{Supplementary Information}

\section{References}

1. Jose J, Snyder JE, Kuhn RJ (2009) A structural and functional perspective of alphavirus replication and assembly. Future Microbiol 4: 837-56.

2. Suhrbier A, Jaffar-Bandjee, MC, Gasque P (2012) Arthritogenic alphaviruses--an overview. Nat Re Rheumatol 8: 420-9.

3. Robinson MC (1955) An epidemic of virus disease in Southern Province, Tanganyika Territory, in 1952-53. I. Clinical features. Trans R Soc Trop Med Hyg. 49: 28-32.

4. Schilte C, Staikowsky F, Couderc T, Madec Y, Carpentier F, et al. (2013) Chikungunya virus-associated long-term arthralgia: a 36-month prospective longitudinal study. PLoS Negl Trop Dis 7: e2137.

5. Sissoko D, Malvy D, Ezzedine K, Renault P, Moscetti F, et al. (2009) Post-epidemic Chikungunya disease on Reunion Island: course of rheumatic manifestations and associated factors over a 15-month period. PLoS Negl Trop Dis 3: e389.

6. García-Arriaza J, Cepeda V, Hallengard D, Sorzano CO, Kummerer BM, et al. (2014) A novel poxvirus-based vaccine, MVA-CHIKV, is highly immunogenic and protects mice against chikungunya infection. J Virol 88: 3527-47.

7. Roy CJ, Adams AP, Wang E, Plante K, Gorchakov R, et al. (2014) Chikungunya vaccine candidate is highly attenuated and protects nonhuman primates against telemetrically monitored disease following a single dose. J Infect Dis 209: 1891-9.

8. Kam YW, Lum FM, Teo TH, Lee WW, Simarmata D, et al. (2012) Early neutralizing IgG response to Chikungunya virus in infected patients targets a dominant linear epitope on the E2 glycoprotein. EMBO Mol Med 4: 330-43.

9. Tretyakova I, Hearn J, Wang E, Weaver S, Pushko P (2014) DNA vaccine initiates replication of live attenuated chikungunya virus in vitro and elicits protective immune response in mice. J Infect Dis 209: 1882-90. 
10. Hallengard D, Kakoulidou M, Lulla A, Kummerer BM, Johansson DX, et al. (2014) Novel attenuated Chikungunya vaccine candidates elicit protective immunity in C57BL/6 mice. J Virol 88: 2858-66.

11. Smith TJ, Cheng RH, Olson NH, Peterson P, Chase E, et al. (1995) Putative receptor binding sites on alphaviruses as visualized by cryoelectron microscopy. Proc Natl Acad Sci USA 92: 10648-52.

12. Pal P, Dowd KA, Brien JD, Edeling MA, Gorlatov S, et al. (2013) Development of a highly protective combination monoclonal antibody therapy against Chikungunya virus. PLoS Pathog 9: e1003312.

13. Chua CL, Chan YF, Sam IC (2014) Characterisation of mouse monoclonal antibodies targeting linear epitopes on Chikungunya virus E2 glycoprotein. J Virol Methods 195: 126-33.

14. Lum FM, Teo TH, Lee WW, Kam YW, Renia L, et al. (2013) An essential role of antibodies in the control of Chikungunya virus infection. J Immunol 190: 6295-302.

15. Goh LYH, Hobson-Peters J, Prow NA, Gardner J, Bielefeldt-Ohmann H, et al. (2013) Neutralizing monoclonal antibodies to the E2 protein of chikungunya virus protects against disease in a mouse model. Clin Immunol Orlando Fla 149: 487-97.

16. Verma P, Bhatnagar S, Kumar P, Chattree V, Parida MM, et al. (2014) Analysis of antibody response (IgM, IgG, IgG3) to Chikungunya virus using panel of peptides derived from envelope protein for serodiagnosis. Clin Chem Lab Med 52: 297-307.

17. Nagar PK, Pradhan S, Verma P, Joshi G, Amrita Singh, et al. (2016) Mapping and Immunological Response of Immunodominant B and T cell Epitopes of E2 Glycoprotein of Chikungunya Virus. MOJ Immunol 4: 1-10.

18. Nagar PK, Gupta DL, Parida MM, Rao DN (2016) Identification of immunodominant epitopes of el and nucleocapsid proteins of chikungunya virus with neutralizing capacity. Int J Curr Med \& Pharma Res 2: 898-905.

19. Ciesielski MJ, Kazim AL, Barth RF, Fenstermaker RA (2005) Cellular antitumor immune response to a branched lysine multiple antigenic peptide containing epitopes of a common tumor-specific antigen in a rat glioma model. Cancer Immunol Immunother 54: 107-19.

20. Oscherwitz J, Yu F, Cease KB (2009) A heterologous helper T-cell epitope enhances the immunogenicity of a multiple-antigenic-peptide vaccine targeting the cryptic loop-neutralizing determinant of Bacillus anthracis protective antigen. Infect Immun 77: 5509-18.

21. Uppada SB, Bhat AA, Sah A, Donthamshetty RN (2011) Enhanced humoral and mucosal immune responses after intranasal immunization with chimeric multiple antigen peptide of LcrV antigen epitopes of Yersinia pestis coupled to palmitate in mice. Vaccine 29: 9352-60.

22. Ali R, Kumar S, Naqvi RA, Rao DN (2013) B and T cell epitope mapping and study the humoral and cell mediated immune response to B-T constructs of YscF antigen of Yersinia pestis. Comp Immunol Microbiol Infect Dis 36: 365-78.

23. Agarwal A, Singh AK, Sharma S, Soni M, Thakur AK, et al. (2013) Application of real-time RT-PCR in vector surveillance and assessment of replication kinetics of an emerging novel ECSA genotype of Chikungunya virus in Aedes aegypti. J Virol Methods 193: 419-25.

24. Lazoura E, Lodding J, Farrugia W, Day S, Ramsland PA, et al. (2009) Non-canonical anchor motif peptides bound to MHC class I induce cellular responses. Mol Immunol 46: 1171-8.

25. Tourdot S, Oukka M, Manuguerra JC, Magafa V, Vergnon I, et al. (1997) Chimeric peptides: a new approach to enhancing the immunogenicity of peptides with low MHC class I affinity: application in antiviral vaccination. J Immunol 159: 2391-8.

26. Masrinoul P, Puiprom O, Tanaka A, Kuwahara M, Chaichana P, et al. (2014) Monoclonal antibody targeting chikungunya virus envelope 1 protein inhibits virus release. Virology 464-465: 111-117.

27. Fric J, Bertin-Maghit S, Wang CI, Nardin A, Warter L (2013) Use of human monoclonal antibodies to treat Chikungunya virus infection. J Infect Dis 207: 319-22.

28. Barksby HE, Lea SR, Preshaw PM, Taylor JJ (2007) The expanding family of interleukin-1 cytokines and their role in destructive inflammatory disorders. Clin Exp Immunol 149: 217-25.

29. Vilcek J, Lee TH (1991) Tumor necrosis factor. New insights into the molecular mechanisms of its multiple actions. J Biol Chem 266 : $7313-6$.

30. Partidos CD, Weger J, Brewoo J, Seymour R, Borland EM, et al. (2011) Probing the attenuation and protective efficacy of a candidate chikungunya virus vaccine in mice with compromised interferon (IFN) signaling. Vaccine 29: 3067-73.

31. de Waal Malefyt R, Hans Y, Roncarolo MG, Spits H, de Vries JE (1992) Interleukin-10. Curr Opin Immunol 4: $314-20$.

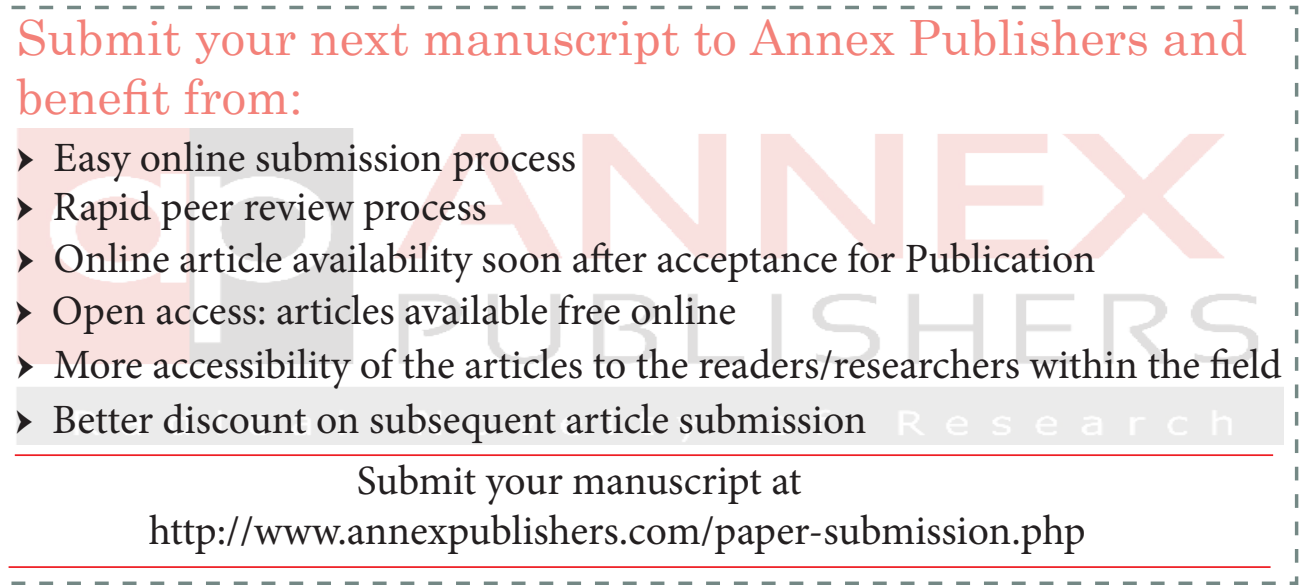

